\title{
Response to Letter to the Editor regarding our article entitled: Management of Chiari I deformity in children and adolescents: A report from the consensus taskforce of the Brazilian Society of Pediatric Neurosurgery
}

\author{
Marcelo Volpon Santos ${ }^{10}$ \\ Antonio Rosa Bellas ${ }^{4}$ Marcia Cristina da Silva ${ }^{5}$ \\ ${ }^{1}$ Department of Surgery and Anatomy, Division of Pediatric \\ Neurosurgery, Faculdade de Medicina de Ribeirão Preto, \\ Universidade de São Paulo, Ribeirão Preto, SP, Brazil \\ 2 Department of Neurosurgery, King's College Hospital NHS \\ Foundation Trust, London, United Kingdom \\ 3 Division of Pediatric Neurosurgery, Universidade Estadual de \\ Londrina, Londrina, PR, Brazil \\ ${ }^{4}$ Division of Pediatric Neurosurgery, Hospital Fernandes Figueira- \\ Fundação Oswaldo Cruz, Rio de Janeiro, RJ, Brazil \\ ${ }^{5}$ Department of Neurosurgery, Hospital João XXIII, Belo Horizonte, \\ MG, Brazil \\ ${ }^{6}$ Department of Neurosurgery, Universidade Federal de São Paulo, \\ São Paulo, SP, Brazil \\ ${ }^{7}$ Department of Surgery and Anatomy, Division of Neurosurgery, \\ Faculdade de Medicina de Ribeirão Preto, Universidade de São Paulo, \\ Ribeirão Preto, SP, Brazil
}

Arq Bras Neurocir 2020;39(4):319-320.

\section{Dear Editor,}

We read with great interest the letter by Rusafa et al., which contains several relevant discussion points regarding our publication. Their remarks certainly shed some more light on the controversial topic that is the Chiari I deformity (CID), and help to better understand this intricate pathology and improve its clinical management, which were also the main objectives of our article in the first place. We are in accordance with most of the comments presented therein; nevertheless, we believe that some of their discussion points need further clarification.

The $5 \mathrm{~mm}$ cutoff measurement of tonsillar ectopia for the diagnosis of CID is definitely a matter of debate in the medical literature. Obviously, it should not be considered in isolation, especially for the indication of surgical treatment. The concomitance of a consistent clinical picture and cerebrospinal fluid flow abnormalities, including syringomyelia (see section 4-clinical indications for surgery - of the original manuscript) are just as significant as the tonsillar ectopia itself. However, our report aimed at providing practical guidance for clinicians

received

September 29, 2020

accepted

September 29, 2020
DOI https://doi.org/

10.1055/s-0040-1719125. ISSN 0103-5355.
Address for correspondence Marcelo Volpon Santos, MD, PhD, Department of Surgery and Anatomy, Division of Pediatric Neurosurgery, Faculdade de Medicina de Ribeirão Preto - Universidade de São Paulo, Av. Bandeirantes, 3900, Vila Monte Alegre - Campus Universitário, Ribeirão Preto, SP,14049-900, Brazil (e-mail: marcelovolpon@usp.br).

dealing with CID, and it is important that they have some clear information to decide whether a given patient should undergo further diagnostic assessments or even be referred to a specialist neurosurgeon. In addition, regarding the need for periodic magnetic resonance imaging (MRI) follow-up, we would like to stress out that our statement pertains to the developing bodies of the pediatric population, in whom not only the posterior fossa structures but also the cerebellar tonsils position and shape might change with time, let alone their anatomical relationships $^{1,2}$; therefore, in our opinion, and specifically for children, radiological follow-up should be recommended and analyzed along with the clinical features.

These concepts should also be brought to mind when discussing the best nomenclature of Chiari I, which is, by the way, very subjective. Probably, the most widely used denomination nowadays is "malformation," coined by Hans Chiari himself, which we find inaccurate because, and as Rusafa et al. also state, Chiari I is not congenital. It is rarely seen in the newborn, and cerebellar tonsillar ectopia in early childhood is most likely the result of a discrepancy between postnatal
Copyright $\odot 2020$ by Thieme Revinter Publicações Ltda, Rio de Janeiro, Brazil
License terms

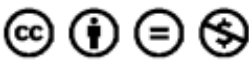


growth of the cerebellum and the posterior cranial fossa. ${ }^{3}$ The word "disease" does not seem appropriate as well, because cerebellar tonsils in Chiari I are either normal or show areas of pressure necrosis, ${ }^{3}$ in contrast with the neuronal disorganization and brainstem dysplasia that have been described, for example, in Chiari II. The term "deformity" seems to highlight the dynamic and acquired nature of Chiari I, which can be modified spontaneously or surgically. For these reasons, and due to the fact that this entity is associated with various other clinical situations, we have accepted the suggestion of DiRocco, ${ }^{4}$ who not only puts aside the term "malformation," but also suggests a contextualized classification distinguishing the different conditions placed under the umbrella definition of CID (such as craniosynostosis, platybasia, craniocerebral disproportion, secondary neurulation abnormalities, bone metabolic disorders, and so forth). Concerning the terms Chiari type 0 and Chiari type 1,5, the authors understand their usefulness, but chose to keep them out of the discussion within the Consensus report for it was a little beyond the scope of the article.

We certainly agree that headaches can be very unspecific, and have varying degrees and characteristics, especially in children. This symptom should not be considered alone as an indication for surgery; nonetheless, it requires careful followup, and surgical therapy might be even considered in cases of refractory persistent headaches with significant radiological findings. Certain headache features, such as occipital location, exertional and worsening with Valsalva maneuvers, are more specifically related to clinically manifested CID.

We also agree that hydrocephalus should be treated prior to consideration for foramen magnum decompression, most often via endoscopic third-ventriculostomy, whenever possible. We thank Rusafa et al. for the reminder and take the opportunity to clarify this issue. Likewise, the use of ultrasonography (US) for the decision to perform duraplasty is still a controversial topic, without consistent scientific evidence hitherto, which is why we have not recommended it officially and only recall that it can helpful in selected cases. We would even add that US is an operator-dependent method, and should be used mostly by neurosurgeons who have good experience with it.

Lastly, we once again definitely agree that there is no evidence to recommend section of the filum terminale, from a physiopathological rationale and a scientific standpoint, for the treatment of CID. We have emphasized this in a previous letter from our group. ${ }^{5}$ At the time the Consensus report was drafted, the work of Milano et al. and the Brazilian Neurosurgery Society Spine Department, ${ }^{6}$ which confirms this assumption categorically, had not been published; nevertheless, it is an outstanding work with very convincing results, for which the authors should be praised. Yet, for the sake of discussion, it is worth mentioning the concept of occult tethered cord syndrome (OTCS), defined as the presence of symptoms consistent with tethering of the spinal cord by the filum, but with the conus in a normal position. ${ }^{7}$ Occult tethered cord syndrome is a well described condition known to occur particularly (but not only) in connective tissue disorders, such as Ehlers-Danlos disease. ${ }^{8}$ This might also be one of the reasons why some patients experience clinical improvement after section of the filum.

We thank again the colleagues for their insightful suggestions and comments, and hope that any major misunderstandings have been clarified. Ongoing discussions such as this one are quintessential to provide us with better knowledge of CID and to improve the quality of care of our patients.

\section{Conflict of Interests}

The authors have no conflict of interests to declare.

\section{References}

1 Schaefer GB, Thompson JN Jr, Bodensteiner JB, Gingold M, Wilson $\mathrm{M}$, Wilson D. Age-related changes in the relative growth of the posterior fossa. J Child Neurol 1991;6(01):15-19

2 Schaefer GB, Thompson JN Jr, Bodensteiner JB, et al. Quantitative morphometric analysis of brain growth using magnetic resonance imaging. J Child Neurol 1990;5(02):127-130

3 Thompson DNP. Chiari I-a 'not so' congenital malformation? Childs Nerv Syst 2019;35(10):1653-1664

4 Di Rocco C. Should we stop using the term "malformation" for Chiari type I? Childs Nerv Syst 2019;35(10):1649-1650

5 Canheu AC, Santos MV, Furlanetti LL, Salomão JFM, de Oliveira RS. The Brazilian Society for Pediatric Neurosurgery: consensus on Chiari I deformity. Childs Nerv Syst 2020;36(01):17-18

6 Milano JB, Barcelos ACES, Onishi FJ, et al. The effect of filum terminale sectioning for Chiari 1 malformation treatment: systematic review. Neurol Sci 2020;41(02):249-256

7 Tu A, Steinbok P. Occult tethered cord syndrome: a review. Childs Nerv Syst 2013;29(09):1635-1640

8 Henderson FC Sr, Austin C, Benzel E, et al. Neurological and spinal manifestations of the Ehlers-Danlos syndromes. Am J Med Genet C Semin Med Genet 2017;175(01):195-211 